\title{
Processo de vulnerabilização e danos ao ofício: a Modernização do Trabalho em questão
}

\author{
Vulnerabilization process and damages to the profession: the \\ Work Modernization in question
}

\begin{abstract}
${ }^{1}$ Maître de conférences em Sociologia da l'Université Paris Ouest Nanterre La Défense. Pesquisadora do Centre de Recherches Sociologiques et Politiques de Paris (CRESPPA), Equipe Genre, Travail, Mobilités, UMR 7217 do Centre Nationale de la Recherche Scientifique (CNRS), Paris, França.
\end{abstract}

Contato:

E-mail: sabine.fortino@gtm.cnrs.fr

Pesquisa financiada pela Agence Nationale de la Recherche

Não existem conflitos de interesse.

Esta reflexão foi apresentada oralmente no dia 10 de agosto de 2011 no seminário internacional "Organização e condições do trabalho moderno: emprego, desemprego e precarização do trabalho", organizado por Aparecida Neri de Souza na Faculdade de Educação da Universidade Estadual de Campinas (Unicamp), dentro de acordo Capes-Cofecub.

Tradução: Selma Venco

Revisão técnica da tradução: José Marçal Jackson Filho

\section{Resumo}

Este estudo teve como objetivo analisar a intensificação e a individualização no âmago da "modernização do trabalho". Esses são compreendidos como processos que, ao se desenvolverem, causam sofrimento e penosidade aos trabalhadores. Nas organizações "modernas", a avaliação do trabalho é realizada cada vez mais sob um único prisma, qual seja, o da performance e o da rentabilidade econômica - aplicada nas relações de serviço e até mesmo do serviço público. É o sentido do trabalho que é afetado. Apoiando-se em uma pesquisa empírica conduzida junto a vendedores de bilhetes e pacotes de viagem de uma grande empresa de transporte, investigou-se a "quebra" dos ofícios como estratégia de assédio organizacional que fragiliza as defesas individuais e coletivas dos assalariados. Identificou-se um sentimento crescente de perda do controle sobre o trabalho por parte dos profissionais e um importante custo relacionado à saúde mental.

Palavras-chave: serviços; precariedade subjetiva; práticas de gestão; desqualificação; sofrimento.

\begin{abstract}
The study analyzes intensification and individualization in the core of "work modernization". Both are seen as processes that cause workers suffering and pain. In "modern" organizations, work has constantly been assessed by a single aspect: performance and economic profitability. When it happens within service relations, even within public service - it is the meaning of work that is affected. Supported by an empiric research involving travel packages and tickets salespersons from a large transport company, "breaking" of professions was investigated as a bullying at work strategy, which deteriorates wage earners' individual and collective defenses. The investigation found these sales professionals have increasingly been feeling they are losing control of their work, at significant cost to their mental health.
\end{abstract}

Keywords: services; subjective precariousness; management practices; deskilling; suffering. 


\section{Introdução}

"O movimento global de melhoria das condições de trabalho que caraterizou o século 20 se inverteu na virada do século 21", já alertara Askenazy (2005, p. 1). Nos últimos anos, na França, os suicídios no trabalho se multiplicaram e se diversificaram, colocando brutalmente luz sobre o mal-estar crescente no trabalho. O caso da France Telecom ${ }^{2}$ se constituiu em verdadeiro trauma nacional com 35 suicídios recenseados em 2008 e 2009. Infelizmente, este recenseamento não terminou, pois ao longo de 2010, os suicídios na France Telecom continuaram.

Estes suicídios ligados ao trabalho, dificilmente quantificáveis em escala nacional, não são com certeza numerosos, mas, como sublinha Christophe Dejours:

um só suicídio em uma empresa constitui, de facto, um problema que afeta toda a comunidade de trabalho, na medida em que sua gênese testemunha de uma degradação profunda do conjunto do tecido humano e social do trabalho. (DEJOURS; BEGUE, 2009, p. 14)

De fato, os suicídios são apenas a parte visível do iceberg: a modernização do trabalho e das empresas degradou significativamente as condições de trabalho e de vida dos assalariados na França, como confirmam os grandes inquéritos quantitativos (como o "SUMER") $)^{3}$ e qualitativos. Os fatores de penosidade "antigos", ligados ao trabalho industrial, que requerem esforços físicos, expondo os assalariados(as) a riscos (ruído, cargas pesadas, vibrações, substâncias tóxicas...) ou a acidentes do trabalho, não desapareceram e até tenderam a se acentuar ao longo dos anos 1990. Contabilizam-se ainda a cada ano aproximadamente $700 \mathrm{mil}$ acidentes do trabalho na França. Nos últimos 15 anos, os cânceres de origem profissional continuaram a aumentar, tais como os de pulmão ligados à exposição dos assalariados(as) a produtos químicos, como óleos minerais utilizados na mecânica de automóveis e na metalurgia, ou ainda, à poeira de madeira, à pintura, ao amianto. Mais amplamente, é a poliexposição dos assalariados às substâncias tóxicas que é o fato marcante (mas, em geral, o mais invisível), revelado por Annie Thébaud-Mony (2006; 2008). Assiste-se, por outro lado, nos últimos 20 anos, a uma verdadeira intensificação do trabalho, tanto no meio industrial, quanto no setor terciário, que leva a uma deterioração precoce e intensa dos corpos. Segundo a pesquisa SUMER, o exemplo dos agravos musculoesqueléticos - que se associam ao trabalho intenso e repetitivo - é gritante sob este prisma. Seu número foi multiplicado por $13 \mathrm{em} 10$ anos, representando $75 \%$ das doenças profissionais reconhecidas e indenizadas e acometendo várias centenas de milhares de assalariados (sobretudo mulheres) declarados inaptos ao trabalho. No setor de serviços, as exigências profissionais foram igualmente intensificadas. Assim, a investigação SUMER dá ênfase na forte pressão exercida pela demanda externa (i.e., o público ou a clientela) sobre o ritmo de trabalho dos assalariados. Ela mostra também o mal-estar e o estresse gerados por um trabalho "pressionado" pela obrigação de abandonar uma tarefa para efetuar outra, pela existência de tensões recorrentes (com a hierarquia, os colegas e o público), que podem degenerar em situações de violência (GUIGNON; HAMON-CHOLET, 2003; BUÉ; SANDRET, 2007).

A degradação do mercado de trabalho francês desde o início dos anos 1980, que se acentuou com a crise de 2008, tem igualmente sua parte de

\footnotetext{
${ }^{2}$ Fonte: SUICIDES à France Télécom: l'entreprise mise en examen pour harcèlement moral. França: Le Monde, 4 jul. 2012. Disponível em: $<$ http://www.lemonde.fr/economie/article/2012/07/04/suicides-a-france-telecom-didier-lombard-mis-en-examen-pour-harcelement-moral_1729208_3234.html >. Acesso em: 10 jun. 2012.

${ }^{3}$ A investigação SUMER [sigla de Surveillance Médicale des Risques Professionnels (N.T.: em português, vigilância médica dos riscos profissionais)] foi iniciada no final dos anos 1980, mas verdadeiramente lançada em 1994. Ela é dirigida pelo DARES (Instituto de Pesquisa do Ministério do Emprego) e pela DGT (Inspeção Médica do Trabalho). Visa a descrever as "exigências organizacionais, as exposições profissionais físicas, biológicas e químicas às quais estão expostos os trabalhadores". Os dados são recolhidos pelos médicos do trabalho que aplicam questionários aos assalariados de sua empresa.

${ }^{4}$ N.T.: A autora emprega no original a palavra penibilité, aqui traduzida por penosidade, embora seu emprego no Brasil seja, de modo geral, menos abrangente. Penibilité é, de um lado, um objeto de pesquisa atual das ciências sociais na França e considerado um conceito em construção, que procura responder à crescente demanda social apresentada por diversas categoriais de trabalhadores devido à degradação de suas condições de trabalho. Por outro lado, a caracterização da penibilité é utilizada pelos sindicatos na negociação social junto às empresas e ao poder público. Considera-se que, no Brasil, a categoria penosidade porta frequentemente um caráter objetivo (e, portanto, mensurável), especialmente no campo do direito do trabalho. Ressalte-se que o estudo da penibilité considera também a dimensão subjetiva, a exemplo do analisado por Leny Sato (As implicações do conhecimento prático para a vigilância em saúde do trabalhador. Cadernos de Saúde Pública, v. 12, n. 4, p. 489-495, 1996), ao ponderar que a compreensão da literatura sobre o tema é estrita à vinculação ao trabalho que requer esforços físicos demasiados, realizados em alto mar, nas alturas ou a céu aberto. Contudo, pela perspectiva do trabalhador, "o que nucleia o conceito, ou seja, o cerne do problema, é o controle, que remete justamente à relação dos trabalhadores com os contextos de trabalho, não se reduzindo a penosidade apenas à presença desses problemas e sim à condição de sujeito na relação de trabalho, onde o incômodo, o sofrimento e o esforço estão presentes. Em outras palavras,neste caso, para o trabalhador, o problema não é o que se denomina de 'risco', mas a relação mantida com o trabalho e suas condições, possibilitada pelo contexto organizacional” (SATO, 1996, p. 492).
} 
responsabilidade no que tange aos danos à saúde. Os assalariados com vínculos precários, temendo por seu emprego, "aceitam" empregos de qualidade ruim, submetendo-se a condições de trabalho difíceis, até indignas (ARDENTI; GORGEU; MATHIEU, 2010; GORGEU; MATHIEU, 2011). Os estudos revelam que de fato os empregadores têm tendência a prescrever ritmos e trabalho intenso contínuos de forma mais constrangedora para os precários do que para os trabalhadores estáveis. Além disso, a falta de formação e a impossibilidade de se apropriar das rotinas do ofício são fatores de risco importantes para os precários. De fato, os assalariados com contrato de curta duração ou de trabalho temporário estão mais frequentemente expostos aos agravos musculoesqueléticos e têm taxas de acidentes mais elevadas do que os assalariados com contrato por tempo indeterminado (DONIOL-SCHAW, 2001). De forma mais abrangente, o impacto à saúde dos percursos profissionais precários começa a ser esclarecido graças ao inquérito Santé et Itinéraire Professionnel (SIP): distúrbios do sono, presença, por vezes repetida, de episódios depressivos maiores, saúde mencionada como ruim ou média com dificuldades motoras ou limitações de atividade... Esses impactos estão mais frequentemente presentes entre os assalariados com percursos profissionais precários (instáveis, com períodos de desemprego e forte mobilidade no emprego) do que entre os estáveis (COUTROT et al., 2010).

Em realidade, a precarização do emprego e o avanço da precariedade social (APPAY, 1997; CASTEL, 1995; 2007) fragilizaram os laços "emprego/assalariado". Ora, o impacto destas transformações sobre o mal-estar dos assalariados tornou-se considerável.

\section{Procedimentos metodológicos}

A pesquisa que ora apresentamos foi realizada entre 2007 e 2010. De caráter qualitativo, ela se apoiou em diversas fontes, quais sejam: entrevistas semidiretivas, observações nos locais de trabalho, análise de documentos institucionais tanto da empresa, quanto do sindicato. O local de realização da pesquisa foi a região parisiense, em função de, por um lado, caracterizar-se como o maior centro de circulação ferroviária do país e, por essa razão, concentra o maior número de assalariados, bem como de passageiros. E, por outro, configurar-se como uma região cujas instalações e equipamentos envelheceram e, portanto, estão mais sujeitos a panes e problemas de interrupção de circulação de trens. Esses aspectos, observou-se, constituem-se também como fonte de tensão no trabalho (FORTINO; LINHART, 2011).

\section{Precarização e sentido do trabalho, noções no âmago da abordagem da pesquisa}

Precarização e sentido do trabalho são dois aspectos, que se destacam particularmente na modernização do trabalho, a serem desenvolvidos neste artigo, pois estão no coração do sentimento particularmente negativo a respeito do trabalho que os assalariados possuem na França. Veremos em um primeiro momento o que se poderia chamar de danos à definição do ofício elaborada coletivamente pelos trabalhadores e, em um segundo momento, os efeitos das lógicas gerenciais modernas.

Controlados contra sua vontade, recompensados ou punidos em relação a fatores pelos quais não são diretamente responsáveis, avaliados apenas por critérios quantitativos de desempenho que não considera o trabalho efetuado... Os assalariados que encontramos estão confrontados a verdadeiro questionamento quanto ao sentido de seu trabalho. Ora, como mostraram psicólogos e psicanalistas do trabalho, o sentido do trabalho encontra-se no coração da relação com o trabalho. Reconhecer-se em seu trabalho, praticar sua atividade profissional segundo as regras do ofício adquiridas graças à formação, transmitida pelo coletivo de pares, colegas e aceitas por cada um, tentar fazer um belo trabalho a partir de uma definição coletiva do seu significado, são essas as condições necessárias para que o trabalho seja vivido de forma satisfatória para a saúde física e mental.

Certamente o real resiste com frequência e os assalariados experimentam, às vezes de forma dolorosa, que o trabalho é confrontação com os outros, com circunstâncias e resistências que podem a qualquer momento surgir. Mas enquanto o trabalho que se faz conserva um sentido, uma utilidade, uma beleza (para si e para os outros), desta resistência ao real pode nascer o prazer, a satisfação (DEJOURS, 2001). Além disso, enquanto subsistem debates coletivos sobre o ofício e até disputas (CLOT, 1999; 2008), enquanto o sentido do trabalho permanece um desafio coletivo para os assalariados, a saúde no trabalho não corre perigo.

Ora, como mostrou notadamente Danièle Linhart (1991, 2009b), o trabalho está sendo vivido no modo pessoal. Sozinhos, isolados e fragilizados pela precarização do emprego e do trabalho (LINHART, 2009a), desafiados a atingir objetivos cada vez mais complexos, os assalariados têm cada vez mais dificuldade em se manter no trabalho, a suportar um investimento mais exigente na sua duração (BERTAUX-WIAME; FORTINO; LINHART, 2011).

Assim, ligado à questão do recuo dos coletivos de trabalho, o estudo das lógicas gestionárias e gerenciais modernas estará no coração da análise. Como 
isto foi mostrado nas pesquisas atuais da sociologia da gestão, veremos o papel dos dispositivos de gestão que "tecem em torno dos assalariados uma rede de exigências numéricas, subordinadas a uma visão hegemônica da organização que se apresenta como a realidade gestionária insuperável” (BENEDETTO-MEYER; MAUGERI; METZGER, 2011, p. 14). Longe de serem neutros ideologicamente, estas lógicas gestionárias tendem, ou melhor, visam a fragilizar no nível objetivo e no subjetivo a relação que entretém os indivíduos com seu trabalho. Tomam por alvos as normas profissionais coletivas elaboradas ao longo do tempo pelos assalariados das quais se deve doravante "desaprender" (METZGER, 2000a; 2000b) e desqualificar em nome da busca de desempenho avaliada sob o prisma exclusivo da rentabilidade econômica. Ora, as normas profissionais são recursos que protegem os assalariados, permitindo-lhes dizer o que, no trabalho requisitado, é justo, adequado, possível ou não, que armam e legitimam sua resistência a partir do saber e da expertise conferidos pelo exercício do ofício. Compreende-se, então, porque o enfraquecimento dos ofícios se torna um temível instrumento de dominação e de aceitação das reformas de inspiração neoliberal, em particular nos serviços públicos.

Uma pesquisa empírica realizada recentemente (FORTINO, 2010) junto a agentes comerciais e vendedores de uma grande empresa pública de transportes (Pegaze) permitirá sustentar esta análise. ${ }^{5}$ Esta pesquisa, de natureza qualitativa, apoia-se sobre um material e fontes diversas: entrevistas semiabertas (individuais e coletivas), observações in situ do trabalho e de ações coletivas, estudo de documentos internos (do sindicato, do jornal "oficial" da empresa). Pretendíamos identificar, a partir da experiência dos assalariados, as novas formas de exigências profissionais ligadas à modernização do trabalho que poderiam provocar danos à sua saúde (física ou mental) enquanto eram vividas sob o registro do sofrimento e da penosidade. O trabalho de campo foi efetuado na região parisiense porque nela se concentra o maior "nó" da circulação ferroviária, tendo por corolário efetivos de assalariados muito importantes, que devem gerir centenas de milhares de passageiros a cada dia e um tráfego denso.

\section{Uma empresa pública no desafio da modernização}

Desde o início dos anos 2000 - o que corresponde ao que se nomeia internamente a "virada comercial da empresa" - assistem-se, na empresa, transformações em todas as direções da organização dos serviços e do trabalho. O desafio "oficial" era importante: transformar a "velha" empresa pública ao final de seu monopólio histórico sobre os transportes ferroviários, conforme as injunções europeias de liberalização dos mercados públicos anunciados desde o final dos anos 1980; colocá-la em condições para enfrentar a concorrência do setor privado nos serviços de frete (2006) e em seguida no transporte internacional de viajantes ${ }^{6}$ (2010) e ganhar a "guerra econômica" que, na "ideologia gestionária", ocupa representação dominante no mundo moderno (DE GAULEJAC, 2006, p. 32). Se nesse momento a questão da financeirização e da privatização da empresa pública estudada não é ainda imposta (contrariamente a outros casos, como os transportes aéreos, as telecomunicações, a energia, a água... hoje passados para o controle do setor privado), é, no entanto, uma "lógica de privatização" (JEANNOT, ROUBAN, 2009) que vai se desenvolver. Rentabilidade e eficácia econômica tornam-se o leitmotiv de seus dirigentes que justificavam assim uma metamorfose em marcha forçada na empresa. Dinamizar os serviços, as vendas, as organizações, os assalariados, o diálogo social, a imagem, a comunicação... Os caminhos da modernização eram (e ainda o são) múltiplos. Ao mesmo tempo - mesmo que este objetivo, mais "oficioso", não aparecesse nos discursos oficiais -, a vontade da direção de retomar o controle sobre a empresa - que conheceu em 1995 uma greve muito importante ocasionando a suspensão de todas as circulações durante mais de um mês, assim como a diminuição "forçada", pelo movimento social, dos projetos de reformas do estatuto dos assalariados da empresa - não está ausente, muito pelo contrário, das intenções da modernização.

\footnotetext{
${ }^{5}$ Pegaze é um nome fictício. A investigação foi realizada entre dezembro de 2007 e janeiro de 2010 com a participação de Cyril Chavantré. Ela se inscreve em uma pesquisa mais abrangente, financiada pela Agence Nationale de la Recherche (N.T.: Agência Nacional da Pesquisa), sobre o tema "a modernização das penosidades do trabalho e do emprego" (sob a direção científica de D. Linhart) e realizada com a colaboração de vários pesquisadores, entre os quais Sarh Neetschen, Julien Choquet, Marc Perrenoeud, Rachid Bouchareb. Os campos de investigação, situados no setor de serviços (terciário), assim como em organizações do serviço público francês, foram múltiplos: comércio, ensino público, transportes públicos ferroviários, empresas de serviços de informática, ofícios de acolhimento e da segurança das instalações, telecomunicações. Neste texto, apresentamos apenas os casos dos agentes comerciais e vendedores do transporte ferroviário; em outras contribuições foram enfocados os condutores de trem e os professores (FORTINO; LINHART, 2011).

${ }^{6} \mathrm{~A}$ liberalização do transporte ferroviário na Europa conheceu diversas etapas e levou quase 25 anos devido às fortes resistências dos Estados com relação à transformação deste setor. Se, desde 1991, a diretiva " $91 / 440$ de 29 de julho de 1991, relativa ao desenvolvimento das estradas de ferro comunitárias", permite o direito de acesso (limitado) à rede ferroviária francesa por empresas de transporte de outros países da União Europeia, foram verdadeiramente determinantes os pacotes (de leis) ferroviárias adotadas em 2001, 2004 e 2007. No dia 1ํo de janeiro de 2007, o conjunto do frete, inclusive doméstico, foi liberalizado; o serviço internacional de viajantes foi aberto no dia $1^{\circ}$ de janeiro de 2010 . Maiores detalhes podem ser encontrados no rapport d'information ao Sénat (N.T.: relatório de informação do Senado) número 20 sobre 'La libéralisation des transports ferroviaires dans I'Union Européenne"' (N.T.: A liberalização dos transportes ferroviários na União Europeia) (12 de fevereiro de 2009).
} 


\section{It's time to move ${ }^{7}$ : reorganizações inces- santes que fragilizam os coletivos de trabalho}

Ano após ano, sucederam-se, na empresa, fases múltiplas de reorganização e outros reagrupamentos de atividades até então realizados em serviços diferentes. Estes reagrupamentos foram completados pela instauração de novos recortes "geográficos" e administrativos (que modificam a afetação dos assalariados, mudando a cadeia hierárquica da qual dependem, modificam as colaborações antigas com os colegas...). Estes novos reagrupamentos acompanharam-se de redefinições (por vezes contraditórias no tempo) das atividades a efetuar, visando tanto a mais especializações profissionais, quanto a uma maior polivalência.

Estas transformações incessantes e aceleradas da organização interna da empresa criam nos assalariados um sentimento muito forte de perda de orientação e de confiança nas estruturas não perenes. Ora, esta falta de controle sobre o ambiente de trabalho gera situações incoerentes, perdas de tempo e de energia múltiplas (para tentar se adaptar a uma organização que se tornou opaca ou incompreensível para os assalariados) e, in fine, gera angústia... Poderia se evocar igualmente o distúrbio gerado pela perda de significação de todas as mudanças organizacionais. Catherine e Noémie ${ }^{8}$ explicam este processo que afeta o trabalho quando não encontram mais sentido profundo nas instruções que lhes pedem aplicar:

A cada 5 anos, muda-se tudo. Colocam pessoas até a uma hora da manhã nas estações [...] e depois, as retiram. Cinco anos depois, são recolocados. É sempre assim! (Noémie, agente comercial, vende passagens para trajetos aos subúrbios)

Eu notei uma coisa [...] é que nesta empresa, parece um pouco com a serpente que morde sua calda, a gente anda sem sair do lugar. Dizem "não é mais preciso fazer isso", [pouco depois] nos dizem "é preciso fazer aquilo" [...] muda-se [...] depois a gente recomeça. Todo o tempo! (Cathérine, agente comercial, vende bilhetes para trajetos inter-regionais ou internacionais)

Mais do que em qualquer outro serviço da empresa, é no setor comercial que as transformações foram as mais rápidas. Conforme afirmação de um sindicalista entrevistado, este setor constituiu um "verdadeiro laboratório de mudanças" (que depois se estendeu aos setores de manutenção, de condução etc.) tanto do ponto de vista das técnicas de venda, quanto da gestão de carreiras ou da avaliação de competências. No espaço de alguns anos, tudo, ou quase tudo, mudou para os assalariados.

\section{Gestão por atividades e empobrecimento do ofício}

Assim, a gestão por atividades, implantada no início de 2000, instaurou barreiras estanques entre os assalariados do setor comercial, em função dos ofícios (recepção ou venda) e em função dos tipos de bilhetes vendidos (para subúrbio, para trajetos nacionais ou internacionais). Daí em diante, a gestão das carreiras é separada, as avaliações são distintas e a possibilidade de passar de um serviço ao outro é muito limitada, quase inexistente. Os assalariados mais antigos, que conheceram aquela época, como dizem "eles faziam tudo em uma estação ou quase tudo", consideram a gestão por atividades como um fator importante de empobrecimento de seu trabalho e uma forma de desqualificação.

\begin{abstract}
Eu trabalhava no guichê, eu ficava na estação para fazer a recepção dos viajantes [...] Eu fazia muitas coisas sempre em relação aos viajantes [...] Era mais agradável porque a gente via outras pessoas, outros ofícios... (Testemunha Catherine)

O que eu gostava, eu, antes, é que era muito variado. (confirma Annick, agente comercial, vende bilhetes para trajetos inter-regionais ou internacionais)
\end{abstract}

$\mathrm{Eu}$, antes, eu tinha, todavia, uma diversidade no meu trabalho. No nível comercial, a gente podia prestar um conjunto de serviços porque a gente podia responder a um máximo de pessoas, porque a gente tinha conhecimentos um pouco de tudo. (Noémie)

Para os mais jovens, ou seja para os assalariados que conheceram a gestão por atividades desde seu recrutamento, esta lhes aparece como uma limitação importante de sua carreira. Uma vez recrutado no guichê de uma estação de subúrbio, não se pode esperar evoluir para a venda de bilhetes nacionais ou internacionais, exceto se passar por entrevistas de seleção, que são muito seletivas. Em todo o caso, a gestão por atividades introduz uma lógica de ultraespecialização das tarefas sobre a qual, após Taylor, contam os dirigentes para fazer produzir mais e mais rápido; ela é, assim, uma ferramenta maior de individualização dos assalariados e atinge os coletivos de trabalho.
Agora, é o isolamento [confia Mathieu], não há mais qualquer comunicação entre os agentes, ninguém mais sabe o que se passa em outros lugares [...]. Antes os agentes de recepção trabalhavam na venda, e da venda passavam a recepção, com uma riqueza de conhecimentos. E depois no cotidiano, quando havia problemas operacionais, era uma felicidade trabalhar com pessoas que conheciam o trabalho dos outros. (Agente comercial, vende bilhetes para trajetos inter-regionais ou internacionais)

\footnotetext{
${ }^{7}$ Este slogan (de origem gerencial) designa o programa implantado pela Direção da France Telecom que obrigava seus executivos a mudar de posto a cada três anos.

${ }^{8}$ Os nomes dos entrevistados neste trabalho são fictícios a fim de preservar o seu anonimato.
} 
A gestão por atividades contribui, assim, ao isolamento profissional dos assalariados, o que não fica sem consequências para o "espírito cheminot", ou seja, uma cultura comum dos assalariados das estradas de ferro que uniu durante muito tempo os agentes uns aos outros em torno da ideia de destino coletivo comum.

Quem não trabalha na venda, não tem mais direito de entrar no espaço de venda. Na recepção, é parecido, você não tem direito de entrar nos locais reservados à recepção [...] Enquanto antes, eu entrava em todos os lugares para dizer bom dia, para ver se havia alguém que eu conhecia. (Catherine)

No entanto, a modernização atacou também outras dimensões da atividade sobre as quais é conveniente entrar em mais detalhes, porque ela toca diretamente na definição do ofício de vendedor.

\section{Redefinição do ofício de vendedor: taylorização da relação de serviço e lógicas profissionais inspiradas no setor privado}

Como se pode observar nos serviços de venda por telefone ou outras centrais de teleatendimento, as novas técnicas de venda na empresa - que visam a incitar o consumidor a compra de produtos, que inicialmente, não faziam parte de seu "projeto de compra" - são doravante moeda corrente.

Desde 2000-2001, diálogos de venda cada vez mais aperfeiçoados, precisos, detalhados e os quais é preciso recitar aos clientes (até a última linha) são impostos aos vendedores. Até então, a venda era pouco "enquadrada" e não era verdadeiramente "ritualizada" por fórmulas de polidez preestabelecidas. De fato, se certas questões deviam ser colocadas ao cliente, isso acontecia mais por razões práticas do que por seguir qualquer estratégia comercial. Ao demandar de entrada ao cliente se ele viajava em primeira ou segunda classe, em vagão fumante ou não fumante, em dormitório ou sentado, e se possuía qualquer carta de redução de preço, evitava-se perder tempo em imprimir um bilhete que in fine acabaria não atendendo a seu desejo. Mas como não tinha esquema de discurso preciso a seguir, o agente comercial se focalizava então na sua relação com o cliente, sobre a qualidade da conversa (amabilidade, atenção) e sobre a ajuda que ele podia aportar para organizar sua viagem, aconselhando-lhe certos trens mais rápidos, certas correspondências mais diretas. Depois de 2000, é preciso seguir uma lista pré-construída de observações e questões. Para bem fazê-lo, 4 a 5 minutos são necessários para cumprir esta tarefa.

O problema é que os vendedores tem o sentimento de dever repetir durante toda a jornada, cliente por cliente, as mesmas palavras impostas. A venda perde então uma parte importante daquilo que interessava para aquele que a exercia: o caráter espontâneo, imprevisível, surpreendente às vezes, da relação que se poderia estabelecer com um cliente. "Não somos robôs!" dirá assim uma das pessoas encontradas. É claro que a imposição deste diálogo de venda revela claramente a "atividade impedida" da qual fala Yves Clot (1999, 2008). Ele faz obstáculo a relação subjetiva e sensível que o vendedor entretém com seu trabalho e seu cliente. Mas é também o objetivo visado por esta ferramenta informática/comercial que está em jogo. Sua única finalidade é aumentar o volume de vendas, suscitando no cliente o "desejo" de comprar o maior número de serviços pagos possíveis. Assim, o vendedor deve propor compras agrupadas, isto é, combinando a compra de um bilhete à de outro produto. ${ }^{10}$ Independentemente (ou quase) dos desejos expressos ou reais dos clientes. De fato, o diálogo de venda permite à empresa incorporar as práticas cotidianas do ofício de vendedor as lógicas profissionais de rentabilidade e de produtividade que ocorrem no setor privado da economia. Ora, esta concepção da venda se choca com a relação mantida com o trabalho pelos assalariados ligados aos valores do serviço público:

\begin{abstract}
Será que vocês têm estadia? Será que têm necessidade de um carro? Gostariam de receber as bagagens em seu domicílio? É preciso lhes propor uma multiplicidade de serviços que não são gratuitos, hein? O hotel? Não é gratuito. O carro? Não é gratuito. A mala (entregue) no domicílio do cliente? 25 Euros... Portanto, é pouco parecido com os seguros onde se procura vender o seguro do carro junto ao seguro da casa, não? Nós, antes, a gente não conhecia isso. (Catherine)

O discurso comercial evoluiu muito [acrescenta Lila]. Quando a gente vende um bilhete, a gente tem tendência a se engajar em uma conversa, a ter um diálogo, a falar... Mas, agora, é preciso esquecer! Inicialmente, para a rentabilidade, porque é preciso atender " $\mathrm{X}$ " pessoas em certo tempo, mas também porque é preciso tentar que a pessoa aceite um bilhete de primeira classe.
\end{abstract}

\footnotetext{
${ }^{9}$ Sobre o espírito cheminot (N.T.: Cheminot é o adjetivo dado aos trabalhadores ferroviários, pertencentes a esta empresa), ver Goergen (2003) e Christian (2002).

${ }^{10}$ Graças a acordos de parceria comercial com empresas especializadas na locação de veículos ou de reserva de hotéis, a empresa pode propor a seus clientes "pacotes": "trem + carro", "trem + hotel".
} 
É preciso propor também um quarto de hotel, o carro [...] Portanto, as pessoas que não o fazem, que tentam estabelecer contatos verdadeiros com as pessoas, de lhes oferecer o que eles realmente necessitam e não forçar outras coisas [...] as quais não querem, bem, eles são mal vistos. (Agente comercial, vende bilhetes para trajetos inter-regionais ou internacionais)

\section{A qualificação profissional dos vende- dores deteriorada pelas estratégias de marketing da empresa}

É preciso evocar o impacto das estratégias de marketing da empresa sobre o trabalho concreto dos agentes comerciais. Há muito tempo acusada de lucrar de sua situação de monopólio por praticar tarifas elevadas, Pégaze quer mostrar à sua clientela que tomar trem pode ser mais vantajoso que o recurso a outros meios de transporte (aéreo ou rodoviário). Ela afirma uma política tarifária particularmente agressiva, mas opaca. Com efeito, do mesmo modo que, por exemplo, a venda de roupas propõe coleções diferentes a cada 3 meses, até a cada mês, a empresa pratica a multiplicação de operações comerciais, de curta duração e que se renova sem cessar. Estas "operações comerciais" desconectam completamente o produto vendido de seu valor econômico, até então justificado/legitimado por critérios precisos, bem compreendidos tanto pelo vendedor, quanto pelo cliente. Entre estes critérios "clássicos" de fixação de preços, pode-se citar "o número de quilômetros efetuados por um trajeto vendido", o que faz com que quanto maior a quilometragem, mais elevado o preço; ou ainda o tipo de qualidade "excelente" ou "banal" da prestação, simbolizada por tíquetes de "primeira ou de segunda classe".

Doravante, para um mesmo trajeto, podem coexistir dezenas de tarifas distintas sobre as quais o vendedor não é capaz de explicar a variabilidade. Um rápido olhar sobre o sítio da empresa na internet permite tomar a medida desta "desregulação" tarifária. Estão assim propostas tarifas Low cost grande vitesse, Low cost grande vitesse $100 \%$, Low cost grande vitesse dernière minute, Low cost grande vitesse vente flash $^{11}$ que se acrescentam às tarifas Exploration $^{12}$, aos cartões de redução Jeunes, Grand âge, Balade... ${ }^{13}$ Para um trajeto Paris-Marselha, o preço do bilhete varia de 30 a 150 Euros. Além disso, os preços praticados pela empresa na internet e no guichê de uma estação são totalmente diferentes e o vendedor no guichê não tem direito de propor as mesmas tarifas da internet, o que favorece a criação de conflitos com os usuários que, tendo visto na internet bilhetes com bom preço, consideram que o vendedor que têm em face de si demonstra má vontade ou quer enganá-los quando se recusa a vender o bilhete ao mesmo preço da internet.

Os agentes comerciais entrevistados se sentem, dessa forma, quase que incapazes de bem aconselhar os clientes. Seu trabalho se torna rotineiro ou mecânico. Eles se contentam em vender bilhetes sem fornecer nem conselho, nem ajuda aos clientes, como testemunha Mathieu:

Com todas estas tarifas diferentes, os vendedores têm a impressão de serem vendedores ambulantes, mercadores de tapete. Os preços, eles não sabem mais de nada! A gente tem a impressão de vender no atacado! (Agente comercial, vende bilhetes para trajetos inter-regionais ou internacionais)

Por outro lado, o crescimento (pretendido pela empresa a fim de reduzir seus efetivos) da venda pela internet e pelas máquinas automáticas transforma o ofício dos vendedores que, de certa forma, tornam-se "suportes humanos" ou ainda auxiliares das máquinas. Seu trabalho serve de fato para corrigir as falhas técnicas destas ferramentas de alto desempenho, mas frequentemente em pane. Novamente, as tensões com os clientes são frequentes, porque eles têm o sentimento (justificado) de perder muito tempo, pois é preciso antes passar pela máquina passagem cuja duração pode ser considerável, pois as instruções escritas não são sempre claras para um neófito - e, em caso de pane, terminar a compra em um guichê, em uma estação, sem deixar de ter esperado em uma fila.

Para os assalariados, esta mudança de papel em relação ao cliente é ainda percebido como um dano ao ofício. Imprimem um bilhete de trem quando a impressora pessoal do cliente (que o comprou pela internet) está em pane; entregam o tíquete ao cliente que teve um problema na máquina automática... Eles não aconselham mais, não estabelecem qualquer relação com o público. Sem contar que os autômatos, que se multiplicam nas estações, são para eles próprios portadores de uma mensagem clara para os agentes comerciais: aquela das supressões de emprego. De fato, o trabalho dos vendedores se degrada objetivamente, mas também subjetivamente, o medo de perder seu emprego está igualmente presente:

\footnotetext{
${ }^{11}$ N.T.: "Baixo custo em grande velocidade", "Baixo custo em grande velocidade 100\%" "Baixo custo em grande velocidade último minuto", "Baixo custo em grande velocidade venda flash"

${ }^{12}$ N.T.: "Exploração".

${ }^{13}$ N.T: "Jovens", "Grande idade" e "Balada”.
} 
Com o desenvolvimento das novas ferramentas de distribuição - internet, máquinas de venda apenas as pessoas com problemas com elas vêm ao guichê agora. Mas nós [os assalariados], a gente não sabe sempre o que fazer, como reparar um erro. Portanto, é efetivamente ainda mais fonte de tensões do que antigamente, com os viajantes que não conseguem retirar seus bilhetes (nos autômatos)... Hoje, a maioria das pessoas que chegam no meu guichê, são pessoas que vêm trocar seus bilhetes porque a máquina não funcionou, são pessoas que tiveram um problema na internet... Portanto é isso, é mal vivido pelos vendedores, com este duplo medo: um medo que se concretiza com as máquinas que lhes roubam seu trabalho e o medo da agressividade dos clientes... (Valérie, gerente do setor comercial)

O mal-estar destes assalariados atinge, além disso, seu paroxismo quando parte da avaliação de suas competências considera a parte (crescente ou não) das compras efetuadas diretamente sobre os autômatos na estação em que trabalham. Em outras palavras: se os clientes não passam por seu guichê para obter seus bilhetes de trem, mas se viram sozinhos junto às máquinas, os agentes são recompensados. A violência simbólica deste tipo de avaliação - na qual se é avaliado por algo que não se faz (vender) ou sobre o qual não se tem nenhum controle (pois a escolha do cliente ir ou não ao guichê não depende do vendedor) - é muito forte. O que leva tanto Soazic, quanto Cathérine a dizerem que "a gente mata a si mesmo":

A gente tem prêmios quando consegue fazer as pessoas pagarem seu tíquete na máquina e não no guichê. Forte, hein? É completamente contraditório porque a gente se mata fazendo isso. A gente mata nosso posto de trabalho. (Soazic)

Eles nos pediram uma época (...) para explicar aos viajantes como se servir dos outros canais de venda: telefone, autômatos, internet... Era preciso explicar como utilizá-los, portanto, depois, eles não tinham mais necessidade de vir te ver. Nos pedem participar de "como suprimir os guichês". (Cathérine)

\section{Gestão individualizada dos vendedores e senso ético dos agentes públicos}

A gestão individual por objetivos dos agentes comerciais vem levar a cabo a transformação das práticas de venda. Trata-se de mobilizar ao máximo os vendedores para que orientem continuamente sua atividade a fim de atingir as metas redefinidas e aumentadas sem cessar. Por muito tempo coletiva, esta "política de metas de venda" se tornou cada vez mais individual; no início baseada no voluntariado, ela tomou, em certos domínios, forma mais coercitiva - cada vendedor sendo doravante avaliado, remunerado e reconhecido por sua contribuição pessoal às vendas. Além disso, a empresa implementou política dita de designação do melhor vendedor do mês e do melhor vendedor do ano, que oferece ao vendedor de bom desempenho seu lote de retribuições materiais e simbólicas.

Um mês fraco no qual os clientes abandonam as viagens de trem, uma ou duas faltas por doença ou licença maternidade ${ }^{14}$ (o que faz com que, durante certo período, não se venda) e as metas numéricas não são atingidas. O prêmio é então perdido (total ou parcialmente, dependendo do caso). Embora financeiramente, o "golpe seja rude" para os assalariados que recebem um salário baixo, o aspecto financeiro não é o único que lhes traz problema, mas também o efeito deste tipo de gestão por objetivos sobre o sentido de seu trabalho. Com efeito, na maioria das entrevistas, o temor que a "quantofrênia" reinante (DE GAULEJAC, 2005) não leve os vendedores a práticas de "vendas forçadas". Seus temores são às vezes verificados quando, no guichê ao lado, eles vêm seus colegas vender certos produtos para os clientes se valendo de argumentos mentirosos.

$\mathrm{Eu}$, eu tenho clientes, são os “abonados S" [pondera Annick], são pessoas que fazem sempre o mesmo trajeto [...] Para eles é mais interessante ter um abono porque vão pagar $50 \%$ mais barato. Mas não! [Alguns vendedores] vão vender "cartas F" que vão custar 85 euros por ano e que não vão levar à melhor redução para o cliente. Em compensação, estas cartas vão dar dinheiro ao vendedor. Ou então, algumas pessoas vão forçar as vendas de bilhetes de primeira [classe] [...] Eu, eu já recebi pessoas, notadamente idosos, que voltaram para me dizer: "Madame, é muito caro, disseram-me que o trem está completo..." Então, você não vai dizer para as pessoas: "Ah, mas sim! Meu colega quis (atingir mais rápido as metas) vender apenas bilhetes de primeira classe dizendo que a segunda classe estava completa, embora não fosse verdade" [...] Apenas situações como esta! E a gente chega a coisas perversas. (Agente comercial, vende bilhetes para trajetos inter-regionais ou internacionais)

E depois, quando você tem objetivos, você empurra... [confirma bem], você vende tudo para qualquer um [...] No subúrbio, pede-se aos vendedores vender o tíquete de ida e o tíquete de volta. Sistematicamente! Nos impuseram isso nos dizendo: "É para lutar contra a fraude" mas na realidade, as pessoas, eles não se servirão talvez do (tíquete) retorno mas você os empurra a consumir.

\footnotetext{
${ }^{14} \mathrm{Em}$ matéria de igualdade profissional entre homens e mulheres, o fato de ser punido financeiramente durante a gravidez merece ser questionado.
} 
Na realidade, o que se passa por trás das situações de trabalho cotidianas muito concretas é um conflito sobre a própria definição do ofício. Para os agentes comerciais entrevistados, vender é satisfazer os clientes, desenvolver relações e troca, procurar as melhores tarifas... E não propor uma maior número de prestações. Esta definição do ofício - que parece causar tantos problemas em relação aos objetivos econômicos agora fixados pela empresa - é legitimado em nome do serviço público. Ela está frequentemente associada aos valores de desinteresse, do bem coletivo (em oposição aos interesses particulares).

\section{Processos multiformes de fragilização dos assalariados}

O segundo aspecto das transformações do trabalho moderno na empresa revela mais sobre as práticas gerenciais visando a fragilizar a posição dos assalariados e sua capacidade de resistir individual e coletivamente. A gestão pela pressão sobre os objetivos a atingir é uma dimensão importante, com frequência denunciada pelos assalariados, assim como faz parte dos documentos sindicais o tema do assédio organizacional, ${ }^{15}$ mas não é a única.

\section{Retomada do controle dos grupos profissionais e en- fraquecimento dos coletivos de trabalho autônomos}

Nas entrevistas, um período é frequentemente evocado, não tão distante (10 anos antes, no máximo), em que o ambiente de trabalho na Pégaze era mais agradável, mais solidário, mais convivial. Refeições coletivas, intervalos em comum... São, nos dizeres de nossos entrevistados, experiências cada vez menos frequentes. Devido à intensificação do trabalho e à diminuição de efetivos, os assalariados encontrados têm o sentimento de não possuir mais tempo para interagir com seus colegas e as jornadas de trabalho são organizadas de tal modo que os vendedores chegam em seu local de trabalho apenas alguns minutos antes da saída daqueles que os precedem. Todavia, o que se extrai das entrevistas vai para além da "falta de tempo" ou de disponibilidade para criar o coletivo. É certa cultura na qual a identidade cheminote de solidariedade teria se perdido no caminho da modernização da empresa.

Eu, eu conheci "X" [uma grande estação] [...] desde que a gente abria o guichê e havia uma fila imensa de clientes que nos esperavam... mas bem, a gente conseguia assim mesmo fazer as refeições juntos [...] Os vendedores não voltavam no momento preciso de suas pausas, os outros os esperavam, a gente se via. (Annick)

Antes se havia qualquer coisa de errado, a gente baixava a cortina [do guichê] e ia ver o diretor. Mas, todo mundo junto, hein? A gente era muito mais próximo. Agora, as pessoas têm medo, há problemas financeiros também [...] Se alguém era insultado, por exemplo, ninguém queria atender o cliente grosseiro. (Sarah, agente comercial, vende bilhetes para trajetos inter-regionais ou internacionais)

A individualização ou atomização das relações de trabalho é frequentemente interpretada como o crescimento dos individualismos ou dos egoísmos contemporâneos. Mas como não os ver também como resultado de políticas gerenciais deliberadas? A gestão individualizada por objetivos gera uma força aguda de concorrência entre os assalariados. Além disso, seria preciso evocar igualmente a supressão de grandes rituais anuais de sociabilidade - quando a direção local juntava todos os vendedores de uma mesma equipe - e sua substituição por "jornadas de proximidade" cuja finalidade é totalmente outra. Com efeito, uma a duas vezes ao ano, os gerentes do setor comercial convidam os assalariados de sua equipe para passar um dia, todos juntos, fora da estação. Esta "saída" tinha apenas o objetivo de reforçar a coesão e o interconhecimento. Lila e Annick, que participaram desde o início dos anos 2000, contam:

Antes, os 3-4 primeiros anos, quando fui contratada. havia refeições, coisas assim [...] e os vendedores que a gente não via obrigatoriamente, isto permitia vê-los [...] Porque [quando a gente chega ao trabalho] a gente substitui o colega, portanto a gente se cruza. Então, na época, duas vezes no ano, havia as refeições... Isto permitia ter um momento entre nós... mas isto não existe mais [...] Antes, a gente se via. A gente tinha direito a jornadas com todos os colegas, até com os dirigentes, hein? Então era uma jornada paga pela empresa e a gente ia a Versalhes. A gente podia também tomar o trem e partíamos todos juntos para passar o dia em Bruxelas, mas isto acabou, isto acabou. Eles cortaram tudo. (Lila)

\footnotetext{
${ }^{15}$ Em novembro de 2009, durante a jornada de ação da CGT - Confédération Générale du Travail (N.T.: Confederação Geral do Trabalho), organizada para reconhecer a penosidade no trabalho no setor comercial, o 'assédio organizacional' foi um dos temas centrais desenvolvidos nos panfletos distribuídos no dia. De forma geral, a imprensa sindical faz regularmente eco do 'sofrimento dos agentes' ocasionado por práticas gerenciais agressivas e, até mesmo, destrutivas. Assim, em um de nossos terrenos de investigação, uma ação militante sobre a saúde no trabalho foi lançada em 2008 pelo sindicato local da rede sul sob a forma de vários panfletos contendo análises aprofundadas (4 páginas) dos elementos que, aos olhos do sindicato, deterioram a saúde dos ferroviários. O primeiro propunha diversas análises da "revolução gerencial que conhece a empresa", cuja face oculta seria constituída por "estresse, suicídios, assédio, agressões"; o segundo, intitulado "O gerenciamento moderno: uma guerra contra os assalariados", focalizava o questionamento dos direitos dos trabalhadores em uma empresa vista como "uma zona de não direito", sobre a denúncia da "falsa autonomia no trabalho dos assalariados" devido aos objetivos a atingir, sobre a "coerção reforçada e culpabilizante (...) porque o assalariado acredita que é responsável por seu fracasso e que os patrões estão lá para lembrá-los: 'você não é feito para este posto', 'olhe seus colegas que conseguem'... Esta campanha local, no seu início, é rapidamente estendida para outros estabelecimentos da região parisiense.
} 
Eu, eu tive as "jornadas equipe" onde [...] no mínimo, a gente ia a um parque de diversões. Bem, era a história de sair, de relaxar [...] mesmo se o responsável estivesse lá. Isso também, isso muda. (Annick)

As "jornadas de proximidade” substituíram as saídas de convivência. Se o gerente "junta suas tropas", é para transmitir as novas instruções vindas da Direção Nacional, para apresentar os novos produtos que os vendedores terão de propor aos clientes. Como disse Lila, agora, não se brinca mais, "a gente fala de trabalho!"

Agora, existem as "jornadas de proximidade. Os dirigentes e todos os vendedores da área estão lá [...] e a gente fala sobre como a gente pode mudar o trabalho? A gente vê se há coisas para modificar no seio da estação... Tudo permanece muito, muito profissional. Em nenhum momento há "como vocês se sentem? Como vocês percebem seu trabalho". Não há mais isso. Isso, isso não lhes interessa. (Lila)

As "jornadas equipe" tratam-se de "propaganda". Agora a gente deve passar um dia em "X" [cidade na província], começa de manhã com uma espécie de briefing da direção, depois a tarde um tempo livre para visitar a cidade e entre os dois, uma refeição [...] E depois, durante a refeição, há um gerente que vai nos falar das novas fórmulas comerciais. (Annick)

\section{Assalariados em plena atividade per- manente: os controles inesperados e clandestinos do trabalho}

Todavia, os métodos gerenciais que isolam os trabalhadores e fragilizam os coletivos de trabalho podem ir ainda mais longe, submetendo os vendedores a ameaça permanente de um controle inesperado. Estas práticas se desenvolveram na empresa especialmente nos últimos anos. Tratam-se de controles "clandestinos" e in situ do trabalho dos agentes comerciais, feitos por pessoas que fingem ser clientes comuns. Embora os vendedores não possam saber em qual dia ocorrerá a passagem do "investigador" no seu guichê, eles descobrem posteriormente, com seu superior hierárquico, o relatório em que são avaliados. Ora, o que notam estes "investigadores"? Em primeiro lugar e antes de tudo, o bom desenrolar do diálogo de venda, o uniforme completo e o crachá, o aspecto bem limpo e organizado do guichê; em seguida, a atitude do vendedor, sua amabilidade, mas também sua propensão a propor o máximo de serviços pagantes à clientela. Este tipo de controle inesperado é percebido pelos assalariados como uma ameaça ou como uma espada de Damocles que será colocada sobre suas cabeças. A qualquer momento, um "falso cliente" pode colocá-los em dificuldade e apenas em um só período de trabalho pode comprometer semanas ou meses de esforços da parte dos agentes comerciais. Além disso, uma avaliação negativa pode influenciar a gratificação corespondente.
Mas, o que é mais grave ainda aos olhos dos vendedores é que este tipo de avaliação não seria pertinente, pois ela não consideraria suficientemente o ambiente "global" de trabalho. Muito centrado sobre o indivíduo, e isto independentemente das circunstâncias e das situações reais de trabalho, tal tipo de avaliação constituiria uma forma de negação do trabalho real, de suas dificuldades e das interações múltiplas que orientam a ação dos vendedores:

\begin{abstract}
Os vendedores se sentem "vigiados" por estas investigações, mas isto não significa nada. Na reunião, não é dito que na manhã da semana quando você foi investigado, você tinha tido cinco manhãs extremas consecutivas, que a gente estava numa sexta-feira e que no momento, verdadeiramente, você estava cansado neste dia. Ela não diz que, neste dia, houve problemas de atraso na linha de subúrbio, que os clientes se apresentavam ao guichê para brigar com você, que a pessoa teve de administrar um mal-estar no trem [...] Esta investigação, ela não diz nada de tudo isso, mas ela diz se você estava sorridente ou não [quando o investigador passou]! (Ben)
\end{abstract}

\section{Avaliações desconectadas do trabalho real}

Outros tipos de avaliação completamente desconectados, ou quase, do trabalho real efetuado são do mesmo modo feitas na empresa. O prêmio referente a automatização, concedido aos assalariados quando os clientes não vão mais aos guichês, mas compram os bilhetes nas máquinas, já foi evocado. Esta avaliação gera nos vendedores um ressentimento forte que os gerentes não conseguem dissipar:

\begin{abstract}
Em um dia ou um mês, eles calculam qual porcentagem de pagamentos foi efetuada na máquina comparando-a aos pagamentos feitos no guichê. Se a gente obtém a porcentagem de automatização requerida para a estação, a gente tem nosso prêmio [...] Nosso trabalho, agora, é dizer para as pessoas: "vão comprar na máquina ao invés de vir ao meu guichê". A direção nos diz: "mas não se preocupem, a gente lhes dará outras missões. Quando você está ao lado da pessoa, próxima da máquina, qual é a diferença?" Mas, isso não é vender! Acho que é extremamente desvalorizador. (Soazic)
\end{abstract}

Poder-se-ia citar ainda a gratificação para os agentes de recepção pela regularidade dos trens de subúrbio. Assim, quando os atrasos dos trens diminuem nas estações nas quais trabalham estes assalariados, eles são bem avaliados. Contudo, nada em sua ação concreta produz efetivamente a regularidade ou, pelo contrário, atrasos na circulação. Não são condutores, nem reguladores, nem controladores das vias... Apenas agentes de recepção informando os viajantes na plataforma ou no guichê. Às vezes, entram em um trem quando um passageiro está doente para retirá-lo ou ajudar os bombeiros, mas, ainda neste caso, o atraso gerado pelo mal-estar do 
passageiro não decorre de sua ação. O máximo que podem fazer é acelerar a retirada do passageiro para que o trem parta mais rápido.

Na realidade, a avaliação quantitativa do desempenho produzido não faz sentido e leva à negação do trabalho real. Qual é o sentido de uma gratificação desconectada da atividade real, isto é, da ação efetiva dos profissionais? Sem resposta adequada da empresa, os assalariados têm tendência a interpretar isto como falta de reconhecimento de seu trabalho.

\section{Conclusão}

O que o inquérito de campo revelou sobre o mal-estar profundo sentido por muitos assalariados tem na sua essência o sentimento de perda de controle sobre o trabalho, o sentimento de isolamento, a incompreensão devido ao questionamento sobre as lógicas coletivas e profissionais do ofício que a mo-

\section{Referências}

ARDENTI, R.; GORGEU, A.; MATHIEU, R. Caractère soutenable du travail et trajectoires ouvrières: Etudes de cas dans la filière automobile et les industries agroalimentaires. Sociétés Contemporaines, Paris, n. 78, p. 87-111, 2010.

APPAY, B. Précarisation sociale et restructurations productives. In: APPAY, B; THEBAUD-MONY, A. Précarisation sociale, travail et santé. Paris: IRESCOCNRS. 1997. p. 509-553.

ASKENAZY, P. Santé: l'impact des nouvelles formes de pénibilité au travail. Le Monde, Paris, 19 dez. 2005. Disponível em: <http://www.lemonde.fr/talents-fr/ article/2005/12/19/sante-l-impact-des-nouvellesformes-de-penibilite-au-travail_722849_3504.html>. Acesso em: 5 maio 2011.

BENEDETTO-MEYER, M.; MAUGERI, S.; METZGER, J. L. L'emprise de la gestion. La société au risque des violences gestionnaires. Paris: L'Harmattan, 2011.

BERTAUX-WIAME, I.; FORTINO, S.; LINHART, D. Des salariés à bout de souffle. Quand le management réquisitionne la subjectivité au travail des hommes et des femmes. In: DRESSEN, M.; DURAND, J. P. La violence au travail. Toulouse: Octarès, 2011. p. 187-198.

BUÉ, J.; SANDRET, N. Contact avec le public: près d'un salarié sur quatre subit des agressions verbales. Premières Informations et Premières Synthèses, Paris, n. 15.1, p. 1-4, abril 2007. Disponível em: <http:// travail-emploi.gouv.fr/IMG/pdf/2007.04-15.1.pdf $>$. Acesso em: 5 maio 2011.

CASTEL, R. Les métamorphoses de la question sociale. Paris: Fayard, 1995. dernização das empresas escolheu claramente como alvo. Temendo que tais lógicas de ofício fossem utilizadas como recursos de resistência dos assalariados, elas são literalmente esmagadas e o sentido do trabalho se encontra fortemente impactado. O que não fica sem consequência. De tanto procurar se prevenir dos conflitos e das estratégias de preservação/ adaptação dos coletivos de trabalho, as empresas correm o risco de desmotivar de forma importante ou, pior, de desorientar os assalariados aos quais pretendiam mobilizar ao máximo por esta estratégia desestabilizadora.

Manter os assalariados em plena atividade, no temor permanente de fazer mal ou não fazer o suficiente, na dúvida de suas capacidades profissionais, sobre o que se espera deles, pode ser um meio da subordinação, mas é um objetivo de curto alcance porque a "precarização subjetiva no trabalho" (LINHART, 2008; 2009a) que atinge doravante tanto os assalariados estáveis, quanto os precários tem um custo em termos de saúde mental.
. Au-delà du salariat ou en-deçà de l'emploi? L'institutionnalisation du précariat. In: PAUGAM, S. Repenser la solidarité. L'apport des sciences sociales. Paris: PUF, 2007. p. 415-434.

CHRISTIAN, C. Cheminots en grève, ou la construction d'une identité (1848-2001). Paris: Maisonneuve et Larose, 2002.

CLOT, Y. La fonction psychologique du travail. Paris: PUF, 1999.

. Travail et pouvoir d'agir. Paris: PUF, 2008.

COUTROT, T. et al. Parcours professionnels et état de santé. Premières Synthèses et Premières Informations, n. 001, p. 1-10, janv. 2010. Disponível em: http://www. npdc.aract.fr/IMG/pdf/PP_et_ES.pdf $>$. Acesso em: 5 maio 2012.

DE GAULEJAC, V. La société malade de la gestion. Idéologie gestionnaire, pouvoir managérial et harcèlement social. Paris: Seuil, 2005.

La part maudite du management: l'idéologie gestionnaire. Empan, Toulouse, v. 61, n. 1, p. 30-35, 2006 .

DEJOURS, C. Subjectivité, travail et action. La Pensée, Paris, n. 328, p. 7-19, 2001.

DEJOURS, C.; BEGUE, F. Suicide et travail: que faire? Paris: PUF, 2009.

DONIOL-SCHAW, G. Le développement de l'emploi nomade à travers l'intérim et la sous-traitance: travail éclaté, citoyenneté limitée. In: JEANNOT, G.; VELTZ, 
P. (Org.). Le travail entre l'entreprise et la cité. Tour d'Aigues: Editions de l'Aube, 2001. p. 267-286.

FORTINO, S. "Au train où ça va...” Modernisation du travail, modernisation des pénibilités: le cas des conducteurs de train et des agents commerciaux. Relatório de pesquisa. Paris: Agence Nationale de la Recherche, 2010. 120 p.

FORTINO, S.; LINHART, D. Comprendre le mal-être au travail: modernisation du travail et nouvelles formes de pénibilité. Revista Latinoamericana de Estudios del Trabajo (Relet), Rio de Janeiro, v. 16, n. 25, p. 35-67, 2011.

GORGEU, A.; MATHIEU, R. Intérim, conditions de travail et santé: une étude de cas dans la filière automobile en France. In: BELKACEM, R.; KORNIG, C.; MICHON, F. (Org.). Visages de l'intérim en France et dans le monde. Paris: L'Harmattan, 2011. p. 77-98.

GOERGEN, M. L. Cheminots et militants, un siècle de syndicalisme ferroviaire. Paris: Éditions de l'atelier/ Éditions ouvrières, 2003.

GUIGNON, N.; HAMON-CHOLET, S. Au contact avec le public, des conditions de travail particulières. Premières informations et premières synthèses, Paris, n. 9.3, p. 1-7, fevereiro 2003. Disponível em: <http://travail-emploi. gouv.fr/IMG/pdf/publication_pips_200302_n-09-3 contact-avec-public.pdf>. Acesso em: 5 maio $201 \overline{1}$.

JEANNOT, J.; ROUBAN, L. Changer la fonction publique. Revue Française D'Administration Publique, n. 132, p. 665-672, 2009.
LINHART, D. Le Torticolis de l'autruche; l'éternelle modernisation des entreprises françaises. Paris: Le Seuil, 1991.

. Pourquoi travaillons-nous? Une approche sociologique de la subjectivité au travail. Ramonville: Erès, 2008.

Modernisation et précarisation de la vie au travail. Papeles del CEIC, v. 1, n. 43, p. 1-19, 2009a. Disponível em: <http:/www.identidadcolectiva.es/ pdf/43.pdf $>$. Acesso em: 5 maio 2011.

. Travailler sans les autres? Paris: Le Seuil, 2009b.

METZGER, J. L. Entre utopie et résignation. La réforme permanente d'un service public : entre utopie et résignation. Paris: L'Harmattan, 2000a.

. Apport et limite des théories de l'apprentissage organisationnel: le cas de la réforme permanente. Travail et Emploi, Paris, n. 82, p. 73-85, $2000 \mathrm{~b}$

SATO, 1996. Autor citado, incluir dados da referência.

THÉBAUD-MONY, A. Histoires professionnelles et cancer. Actes de la Recherche en Sciences Sociales, Paris, n. 163, p. 18-31, 2006.

. Travailler peut nuire gravement à votre santé. Sous-traitance des risques, Mise en danger d'autrui, Atteintes à la dignité, Violences physiques et morales, Cancers professionnels. Paris: La Découverte, 2008. 